PAPER

\title{
A simple method to calculate solution-phase free energies of charged species in computational electrocatalysis
}

To cite this article: Laura P Granda-Marulanda et al 2021 J. Phys.: Condens. Matter 33204001

View the article online for updates and enhancements.

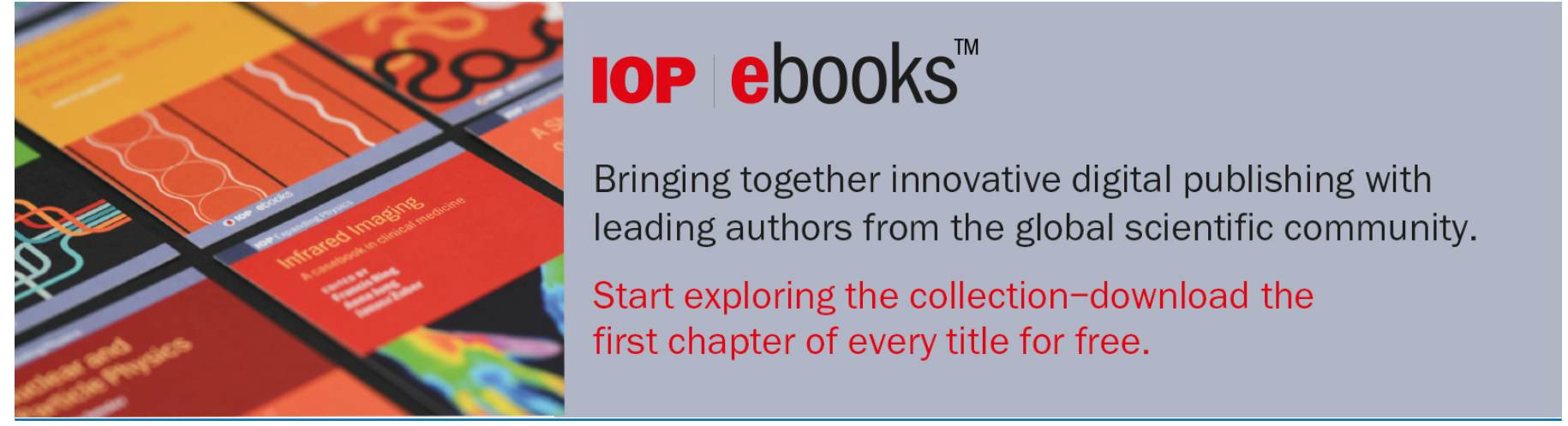

This content was downloaded from IP address 132.229 .202 .55 on $28 / 07 / 2021$ at $15: 39$ 


\title{
A simple method to calculate solution-phase free energies of charged species in computational electrocatalysis
}

\author{
Laura P Granda-Marulanda ${ }^{1}$, lan T McCrum ${ }^{1,2, *}$ and Marc T M Koper ${ }^{1, *}$ (1) \\ ${ }^{1}$ Leiden Institute of Chemistry, Leiden University, PO Box 9502, 2300 RA Leiden, The Netherlands \\ 2 Department of Chemical \& Biomolecular Engineering, Clarkson University, 8 Clarkson Ave., Potsdam, \\ NY 13699, United States of America \\ E-mail: imccrum@clarkson.edu and m.koper@lic.leidenuniv.nl
}

Received 13 January 2021, revised 2 March 2021

Accepted for publication 24 March 2021

Published 27 April 2021

\begin{abstract}
Determining the adsorption potential of adsorbed ions in the field of computational electrocatalysis is of great interest to study their interaction with the electrode material and the solvent, and to map out surface phase diagrams and reaction pathways. Calculating the adsorption potentials of ions with density functional theory and comparing across various ions requires an accurate reference energy of the ion in solution and electrons at the same electrochemical scale. Here we highlight a previously used method for determining the reference free energy of solution phase ions using a simple electrochemical thermodynamic cycle, which allows this free energy to be calculated from that of a neutral gas-phase or solid species and an experimentally measured equilibrium potential, avoiding the need to model solvent around the solution phase ion in the electronic structure calculations. While this method is not new, we describe its use and utility in detail and show that this same method can be used to find the free energy of any ion from any reaction, as long as the half-cell equilibrium potential is known, even for reactions that do not transfer the same number of protons and electrons. To illustrate its usability, we compare the adsorption potentials obtained with DFT of $\mathrm{I}^{*}, \mathrm{Br}^{*}, \mathrm{Cl}^{*}$, and $\mathrm{SO}_{4}{ }^{*}$ on $\mathrm{Pt}(111)$ and $\mathrm{Au}(111)$ and $\mathrm{OH}^{*}$ and $\mathrm{Ag}^{*}$ on $\mathrm{Pt}(111)$ with those measured experimentally and find that this simple and computationally affordable method reproduces the experimental trends.
\end{abstract}

Keywords: computational electrocatalysis, solvation, adsorption

S Supplementary material for this article is available online

(Some figures may appear in colour only in the online journal)

\section{Introduction}

Elucidation and understanding of the complex structure at the electrochemical interface, between electrolyte, adsorbates, and electrode, is one of the main fundamental problems in electrochemistry/electrocatalysis. The advancement of in situ spectroscopic and imaging techniques has allowed fundamental information at the atomic and molecular level to be obtained

* Authors to whom any correspondence should be addressed.
[1-9]. In addition, the increase of computational power has allowed computational tools based on the generalized gradient approximation (GGA) density functional theory (DFT) to provide predictions complementary to experimental results, based on the computed adsorption energetics, thermodynamics, and kinetics of processes at the electrochemical interface [10-15].

The main computational challenges that first-principles DFT simulations face at present are (i) the description of the potential dependence of the electrochemical processes and (ii) the description of the solvated species (protons and charged 
species) in the bulk solution phase and the description of these same species at the metal-electrode interface.

In the first case, the biggest limitation is that the methods available to simulate variation of the electrode potential dependence are computationally more expensive than the traditional simulations, due to the necessity of changing the charge during the simulation to keep the potential constant. [16-18] In periodic simulations, where plane wave basis sets are used, calculating negatively charged species by adding charges to a small supercell can lead to unphysical energies. This is due to the so called 'charge leakage', which are non-wanted interactions with the next periodic representation of the system, and also because of the unphysical distribution of the charge in the cell due to improper screening [19]. To address this, periodic DFT models have been devised to simulate charged systems, by adding a background charge to make the system charge neutral but with the extra requirement of an energy correction afterward [20-22]. Similarly, it has also been proposed to add background charge with a dielectric continuum to prevent charge transfer [23]. Recently, Tölle et al [24] suggested a method to calculate ionization potentials of liquid water in periodic systems, where the finite charge subsystem is embedded and surrounded by an extended subsystem, obtaining comparable results of the ionization potential with experiment data and continuum dielectric models.

The other difficulty faced by DFT simulations is the description of solvated species. The calculated energies within the DFT framework represent systems in the gas phase (or vacuum) at $0 \mathrm{~K}$, instead of systems in solution phase as they are in an electrochemical environment. In general, models that are meant to capture solvation effects in electrochemistry, including explicit solvation [25-31], implicit solvation [32-37] or a combination of the two [38-40], add significant computational expense to the calculation due to the long length and time scales of the solvation structure and dynamics. Explicit solvation is modeled by adding solvent molecules in the simulation cell, where the solvent structure can be based on periodic electronic structure calculations using GGADFT, ab initio molecular dynamics, or classical molecular dynamics [41-43]. Implicit solvation is modeled as a dielectric continuum as described by its experimentally measured dielectric constant and is a model that is in active development and improvement [44-46]. These solvation models can be applied to both solvation in the bulk solution and at the electrode-adsorbate-electrolyte interface. Even though much effort has been devoted to accurately compute solvation energies of protons and ions in solution [47-53], by combining thermodynamic cycles with implicit continuum models [52, $54,55]$, or by calculating the solvation energy of charged species, either with implicit or explicit solvation, it remains a challenging part of computational electrochemistry $[56,57]$.

Fortunately, for ions in bulk solution, thermodynamic cycles can be very practical because they can provide free energies of charged species in the solution-phase by relating the exact free energy of a solution-phase ion to that of a readily and accurately calculated neutral gas-phase or solid-state species, for instance by using experimental redox potentials.
Such thermodynamic cycles allow solution phase free energies to be calculated without the need to model the solvent.

One such thermodynamic cycle which has gained standard, widespread use in computational electrochemistry is the 'computational hydrogen electrode' (CHE) [58], in which the free energy of a proton-electron pair is related to that of hydrogen gas, $\boldsymbol{H}_{(\mathbf{a q})}^{+}+\boldsymbol{e}^{-} \rightleftarrows \frac{1}{2} \mathbf{H}_{2(\mathbf{g})}$, by the definition of the equilibrium potential of the standard or reversible hydrogen electrode (RHE). At a potential of $0 \mathrm{~V} \boldsymbol{U}_{\text {RHE }}$ and standard conditions of 1 bar, and $298.15 \mathrm{~K}$, the proton-electron pair $\left(H^{+}+e^{-}\right)$is in equilibrium with hydrogen gas $H_{2(\mathrm{~g})}$, allowing the free energy of the proton-electron pair to be calculated from neutral $\frac{1}{2} \mathrm{H}_{2(\mathrm{~g})}$. This method allows for the thermodynamics of reactions involving coupled proton-electron transfer to be calculated easily and accurately using DFT.

Many similar thermodynamic cycles have been used to calculate the free energy of other solution phase ions (other than protons). Calle-Vallejo et al used experimentally measured formation energies (of liquid nitric acid and the aqueous nitrate anion) and the DFT calculated free energy of nitric acid in the gas phase to calculate the free energy of the nitrate anion in aqueous solution to examine its adsorption thermodynamics [59]. In a recent study, McCrum et al [60] used two different methods to calculate the free energy of halide anions in solution, so that the thermodynamics of their adsorption to an electrode surface could be determined. In the first method, the energy of the halide anion in vacuum was calculated using DFT, then it was corrected to the aqueous electrolyte by adding on an experimentally measured solvation energy, similar to the method used by Yeh et al [61]. To then convert the energy of the ion-electron couple from an absolute scale to the normal hydrogen electrode scale, a second experimental value is needed, the absolute (vacuum) potential of the hydrogen electrode at standard state $(4.4 \mathrm{~V})$ [62]. In the second method, the authors used an approach similar to that of the CHE, relating the free energy of the aqueous halide anions to that of the gasphase halogens using their experimentally measured standard reduction potentials. This latter method is also described by Hansen et al [63] to study chlorine evolution and Gossenberger et al [64] to construct phase diagrams of halides co-adsorbed with hydrogen on platinum. In another investigation to determine the likelihood of co-adsorption of $\mathrm{ClO}_{4}{ }^{*}$ and $\mathrm{Cl}^{*}$ with $\mathrm{OH}^{*}$ on $\mathrm{Pt}(111)$ [65], the authors used the same method to calculate the free energy of $\mathrm{ClO}_{4}{ }^{-}(\mathrm{aq})$ and $\mathrm{Cl}^{-}(\mathrm{aq})$. In this latter method, the half-cell equilibrium potentials of the redox couples of $\left(\mathrm{Cl}_{2}(\mathrm{~g}) / \mathrm{Cl}^{-}(\mathrm{aq})\right)$ and $\left(\mathrm{ClO}_{4}{ }^{-}(\mathrm{aq}), \mathrm{H}^{+} / \mathrm{Cl}_{2}(\mathrm{~g})\right)$, and the calculated free energies of $\mathrm{Cl}_{2}(\mathrm{~g})$ and $\mathrm{H}_{2} \mathrm{O}(\mathrm{l})$ are needed. The final solution phase free energy of the anions, $\mathrm{ClO}_{4}{ }^{-}$(aq) and $\mathrm{Cl}^{-}(\mathrm{aq})$ is then corrected to their initial experimental concentrations, using the Nernst equation, also similar to the work described by Gossenberger et al [66]. Additionally, various studies have discussed the relevance of thermodynamic cycles often combined with an implicit continuum model to determine solvation energies to calculate $\mathrm{pK}_{\mathrm{a}}$ 's and reduction potentials [52, 54, 55, 67-70].

Therefore, using standard redox potentials to obtain solvation energies or vice versa through thermodynamic cycles is well known, and while many thermodynamic cycles can be 
and have been defined, there is a need to re-visit and illustrate the potential of this conceptually simple, computationally efficient, and transferable method to calculate the reference free energy of any solution phase ion, in bulk electrolyte, far from the electrode surface. Resources containing thousands of redox reactions, such as the standard thermodynamic tables of equilibrium potentials $[71,72]$, are available, and so it is very likely that the species of interest are tabulated there.

In this work, we describe how the free energy of any solvated ion can be calculated exactly from that of a neutral gas-phase or solid-state species and an experimentally measured equilibrium potential, eliminating the need to model solvation for the bulk solution phase species with DFT. We show that, in combination with the CHE, this method works even for half-cell reactions which involve an unequal number of protons and electrons. This is of fundamental importance because achieving robust predictions with computational modeling depends on the choice of the reference state. A solution phase reference state is necessary, for example, for the computation of specific adsorption potentials of ions on electrodes [60, 63-65]. The interactions, between adsorbed ions, the solvent, and reaction intermediates, are of significant importance in catalysis and electrocatalysis, as they can modify bond breaking/formation, adsorption energies, and consequently reaction pathways [73-81] important for catalyst design. Since this method relies on the experimentally measured equilibrium potential, we could argue that it is less ' $a b$ initio' than the CHE, thus we are limited to the availability of the experimental data and we need to be aware of the accuracy of the experimentally measured potential. However, the advantages are (i) that it facilitates the calculation of the free energies of various ions at the same potential scale, which is the scale at which the equilibrium potential sits, and (ii) similar to the CHE, there is no increase in the computational intensity of the calculations, as the calculations rely on neutral gas-phase species. We show examples of how to calculate solution free energies of ions in the context of computational electrocatalysis, and finally we demonstrate how this method can be used by using DFT to examine the thermodynamics of adsorption of $\mathrm{I}^{*}, \mathrm{Br}^{*}, \mathrm{Cl}^{*}$, and $\mathrm{SO}_{4}{ }^{*}$ on $\mathrm{Pt}(111)$ and $\mathrm{Au}(111)$ and $\mathrm{OH}^{*}$ and $\mathrm{Ag}^{*}$ on $\mathrm{Pt}(111)$ and comparing with those measured experimentally.

\section{Methods}

In this section, we first describe the method for calculating the free energy of an ion in solution, and then apply this method to calculate the adsorption free energy of $\mathrm{Cl}^{*}, \mathrm{Br}^{*}, \mathrm{I}^{*}$, and $\mathrm{SO}_{4}{ }^{*}$ on $\mathrm{Pt}(111)$ and $\mathrm{Au}(111)$ and $\mathrm{OH}^{*}$ and $\mathrm{Ag}^{*}$ on $\mathrm{Pt}(111)$.

\subsection{Computational details}

The Vienna ab initio simulations package [82-84] was used to perform the DFT calculations, using a plane-wave basis set and the projector augmented wave approach $[85,86]$. The cut-off energy for the basis set was $450 \mathrm{eV}$. The Perdew-Burke-Ernzerhof, exchange-correlation functional was used [87, 88]. Both the $\mathrm{Pt}(111)$ and $\mathrm{Au}(111)$ surfaces were modeled as a 4 layer slab (or 5 layer slab, in the case of $\mathrm{SO}_{4}{ }^{*}$ on $\mathrm{Au}(111)$ and $\mathrm{Pt}(111)$ ), with the bottom 2 layers frozen at the experimentally measured lattice constants of $3.92 \AA$ and $4.08 \AA$, respectively [89], in a $3 \times 3$ unit cell. A Monkhorst-Pack mesh $k$-space sampling grid [90] of $5 \times 5 \times 1$ and $8 \times 8 \times 1$ were used for $\operatorname{Pt}(111)$ and $\mathrm{Au}(111)$, respectively. To simulate the surfaces, a vacuum spacing $>14 \AA$ between the slabs was set. Dipole corrections were included in the surface-normal direction [91]. Structural optimization was performed until the forces on each atom were below $0.02 \mathrm{eV}^{-1}$. The adsorption thermodynamics for each adsorbate were evaluated at 1/9 monolayer (ML) coverage. $\mathrm{OH}^{*}$ and $\mathrm{SO}_{4}{ }^{*}$ were additionally simulated with co-adsorbed explicit water molecules to approximate the near-surface solvation effect on the adsorption energy. For sulfate adsorption, see equation (1), a $6 \mathrm{H}_{2} \mathrm{O}^{*}$ water bilayer was used as the reactant state and two water molecules were displaced upon $\mathrm{SO}_{4}{ }^{*}$ adsorption, giving a product state with 4 water molecules coadsorbed with $\mathrm{SO}_{4}{ }^{*}$. For $\mathrm{OH}^{*}$, see equation (2), the reference state was three hydrogen-bonded water molecules adsorbed on the surface $\left(3 \mathrm{H}_{2} \mathrm{O}^{*}\right)$, one proton was then removed to create the product state, which was two water molecules co-adsorbed with $\mathrm{OH}^{*}$. While the water adsorbed on the surface in the initial state, and the water remaining on the surface, co-adsorbed with the adsorbate in the product state, were static, and only vibrational entropy changes were considered, the adsorption reaction does include the entropy change associated with the adsorbate displacing adsorbed water molecules into bulk solution ( 2 water molecules displaced for $\mathrm{SO}_{4}{ }^{*}, 1$ for $\mathrm{OH}^{*}$ ). Additional entropy changes of the solvent near the surface are not considered. This method of modeling the effects of nearsurface solvent therefore only approximates the change in entropy upon adsorption. This method also captures only the most local solvating enthalpic interactions, such as hydrogen bonding to the adsorbate and static dipole screening, approximating what could be considered part of the first 'solvation shell' around the adsorbate and surface.

$$
\begin{gathered}
6 \mathrm{H}_{2} \mathrm{O} *+\mathrm{SO}_{4(\mathrm{aq})}^{2-} \rightarrow\left[\mathrm{SO}_{4}+4 \mathrm{H}_{2} \mathrm{O}\right] *+2 \mathrm{H}_{2} \mathrm{O}_{(\mathrm{aq})}+2 e^{-} \\
3 \mathrm{H}_{2} \mathrm{O} * \rightarrow\left[\mathrm{OH}+2 \mathrm{H}_{2} \mathrm{O}\right] *+H^{+}+e^{-}
\end{gathered}
$$

Silver adsorption on $\operatorname{Pt}(111)$ was examined at a coverage of 1 and $2 \mathrm{ML}$, in a $1 \times 1 \operatorname{Pt}(111)$ unit cell, with a $9 \times 9 \times 1$ $k$-space grid. Single gas-phase molecules are calculated in a large box of $(15 \AA \times 15 \AA \times 15 \AA)$, with a $k$-point grid of $1 \times 1 \times 1$. The $0 \mathrm{~K} \mathrm{DFT}$ energy of metallic silver is calculated using a slab model, instead of a $3 \mathrm{~d}$ bulk structure. We varied the slab thickness (above the thickness where the energy of the slab is converged) of a $\operatorname{Ag}(111) 1 \times 1$ unit cell, where the slope of a line fit to the energy versus slab thickness represents the energy of bulk silver, per bulk atom. This slab method allows for a greater cancellation of errors than with a $3 \mathrm{~d}$ bulk structure [92]. The slabs were symmetric, with the middle two layers frozen at the experimentally measured lattice constant.

All free energies of the gas phase species are calculated following equation (3) given further below, at $298.15 \mathrm{~K}$ and $1 \mathrm{~atm}$ of pressure, except for liquid water, which is calculated at its experimentally measured partial pressure at $298.15 \mathrm{~K}$, where 


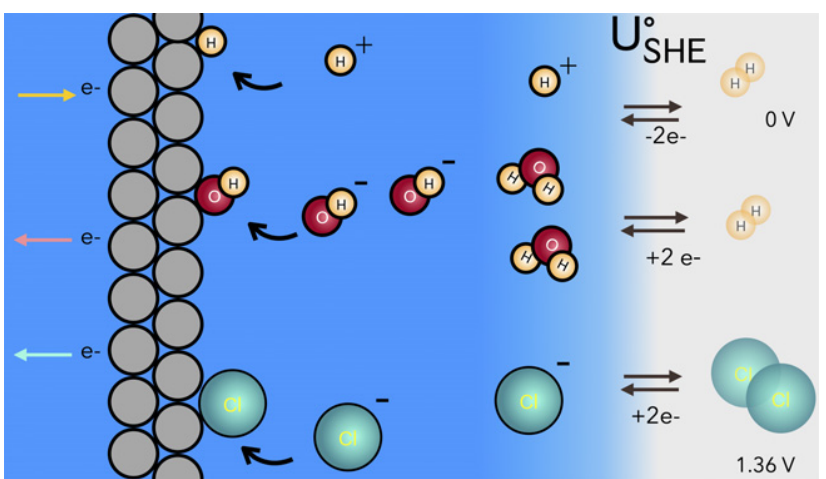

Figure 1. Representation of ions $\left(\mathrm{Cl}^{-}, \mathrm{OH}^{-}, \mathrm{H}^{+}\right)$, in solution phase in equilibrium with gas-phase species at their experimentally measured equilibrium potentials, except for $\mathrm{OH}^{-}$[71], (right), and same ions adsorbed on a generic electrode with 111 facet (left). The reference neutral species for adsorbed $\mathrm{OH}^{*}$ are $\mathrm{H}_{2} \mathrm{O}(\mathrm{l})$ and $\mathrm{H}_{2}(\mathrm{~g})$ using the $\mathrm{CHE}$ at $0 \mathrm{~V} U_{\mathrm{SHE}}^{\circ}$.

basically its gas-phase entropy is corrected by $-0.0887 \mathrm{eV}$ $[58,93] . \mathrm{SO}_{2}(\mathrm{aq})$ was taken as the free energy of $\mathrm{SO}_{2}(\mathrm{~g})$ as correction by its solvation energy $(-0.005 \mathrm{eV})$ [94] does not significantly change the energy. The work function was determined as the difference between the Fermi energy and the one electron potential in vacuum, $\Phi=V-E_{\text {fermi }}$. The partial charges where determined with the AIM Bader analysis [95, 96], using the Bader program from Henkelman's group [97].

The free energy of the solution (aqueous) phase anion is calculated following the method we describe in the following section. Briefly, we use a tabulated value of the experimentally measured equilibrium potential connecting a neutral gas-phase (see figure 1) or solid-state species, with the aqueous phase ion of interest from which the adsorption energies or potentials are calculated. For $\mathrm{I}^{-}, \mathrm{Br}^{-}$, and $\mathrm{Cl}^{-}$, this reaction was the reduction from solid $\mathrm{I}_{2}$ and gas-phase $\mathrm{Br}_{2}$ and $\mathrm{Cl}_{2}$, which at standard state have equilibrium potentials of $0.620,1.094$, and $1.36 \mathrm{~V} U_{\mathrm{SHE}}^{\circ}$ [71]. For iodine, the free energy of solid-phase iodine was calculated as that of gas-phase iodine at a partial pressure equal to its vapor pressure at room temperature [98]. For $\mathrm{SO}_{4}{ }^{2-}$, this reaction was that of sulfur dioxide reduction, with an equilibrium potential at standard state of $0.158 \mathrm{~V} U_{\mathrm{SHE}}^{\circ}$ SHE [71]. For $\mathrm{Ag}^{+}$, the free energy of the aqueous silver cation was calculated from that of metallic silver, with an equilibrium potential of $0.799 \mathrm{~V} U_{\mathrm{SHE}}^{\circ} \mathrm{SHE}$ [71]. For each reaction, the experimentally measured equilibrium potential at standard state was obtained from the data in 'Standard Electrode Potentials and Temperature Coefficients in Water at 298.15 K' [71]. Lastly, for $\mathrm{OH}^{*}$, the free energy of adsorption was calculated relative to hydrogen gas and water, following the CHE method, CHE [58], with a standard equilibrium potential of exactly $0 \mathrm{~V}$ $U_{\text {SHE }}^{\circ}$

\subsection{Determination of the free energy of ions in solution}

The accuracy of the energy of the solution phase ion using thermodynamic cycles depends on how well DFT can represent the neutral species. Therefore, it is crucial to include gas-phase corrections [99-101] or solid-phase corrections [102] to the neutral species from which the ion solution free energy will be calculated. For instance, if one is interested in the solution phase free energy of oxalic acid, although a neutral species, its solution phase free energy can be calculated from $\mathrm{CO}_{2}(\mathrm{~g})$ and its equilibrium redox potential $\left(\mathrm{CO}_{2}(\mathrm{~g}), H^{+} / \mathrm{H}_{2} \mathrm{C}_{2} \mathrm{O}_{4}, \boldsymbol{U}_{\text {SHE }}^{\circ}=-0.432 \mathrm{~V}\right)$. In this case the calculated DFT energy of $\mathrm{CO}_{2}(\mathrm{~g})$ will require a gas-phase correction that is functional dependent.

The free energy of the gas-phase species $X(\mathrm{~g})$ can then be determined with DFT and statistical mechanics following equation (3)

$$
G_{X_{(\mathrm{g})}}=E_{\mathrm{DFT}}+\mathrm{ZPVE}+E_{\mathrm{int}}-\mathrm{TS}+\mathrm{PV}
$$

where ZPVE is the zero-point vibrational energy, $E_{\text {int }}$ includes the vibrational, rotational, and translational contributions (above $0 \mathrm{~K}$ ) to the internal energy, $\mathrm{S}$ the entropy of the gasphase molecule. The internal energy is calculated using statistical mechanics for vibrational, rotational, and translational energy, while the entropy, in this work, is taken from standard thermodynamic tables [72], PV is the pressure-volume contribution to the free energy, obtained as $\mathrm{PV}=N k_{\mathrm{B}} T$ where $N=1$ mole, $k_{\mathrm{B}}$ is the Boltzmann constant and $T$ is the temperature.

In this work, for the solid-state species, the $0 \mathrm{~K}$ DFT energy is taken as an approximation of the free energy of the solid at room temperature.

In the following we show how to obtain the free energy of solution-phase ions from gas-phase species. The first step is to identify a reaction that links the charged species we are interested in with a neutral species that is ideally in the gas phase or in the solid phase, and has a known (experimentally measured) equilibrium potential (which can be found, for example, in equilibrium potential tables, tabulated for many ions) [71, 72]. For example, if we want to determine the aqueous free energy of $\mathrm{Cl}_{(\mathrm{aq})}^{-}$, we can use its standard half-cell reduction reaction, $\frac{1}{2} \mathrm{Cl}_{2(\mathrm{~g})}+e^{-} \rightleftharpoons \mathrm{Cl}_{(\mathrm{aq})}^{-}$, with equilibrium potential $U_{\mathrm{SHE}}^{\circ}=1.36 \mathrm{~V}$ [71]. This reaction links an easy to calculate neutral gas-phase species, $\mathrm{Cl}_{2}(\mathrm{~g})$, with the charged, difficult to model, $\mathrm{Cl}_{(\mathrm{aq})}^{-}$, allowing for the calculation of the free energy of the anion from that of the gas-phase species [60, 63, 64]. The CHE model [58] is an example of such an electrochemical thermodynamic cycle, but it is a special case where the equilibrium potential is defined to be exactly $0 \mathrm{~V} U_{\mathrm{SHE}}^{\circ}($ at $\mathrm{pH}=0$, or $0 \mathrm{~V} U_{\mathrm{RHE}}$ at all $\mathrm{pH}$ ). In the method described here, we will show how to use such a cycle to determine the solution phase free energy of ions using half-cell redox reactions that do not transfer the same number of protons and electrons.

A general representation of how to determine the free energy of solution phase of charged species will be shown in the next sections where we use reactions with an experimentally known equilibrium potential, in two scenarios. The first is for reactions transferring electrons (with no proton transferred with the electrons) for instance, the $\mathrm{Cl}_{2}(\mathrm{~g}) / \mathrm{Cl}^{-}$half-cell redox reaction, and the second for reactions transferring different numbers of protons and electrons, for instance the $\mathrm{SO}_{4}{ }^{2-}$ (aq), $\mathrm{H}^{+} / \mathrm{SO}_{2}(\mathrm{aq})$, half-cell redox reaction, where a different number of protons $\left(4 \mathrm{H}^{+}\right)$and electrons $\left(2 \mathrm{e}^{-}\right)$participate in the reaction. 
2.2.1. Half-cell redox couple with n electrons transferred. The following method has been described in the literature to calculate the free energy of an ion in solution to then construct adsorbate phase diagrams and determine adsorption potentials $[63,64]$.

For the following generic reaction:

$$
\frac{1}{2} A_{2(\mathrm{~g})}+n e^{-} \rightleftharpoons A_{(\mathrm{aq})}^{n-}
$$

the change in free energy on a given potential scale is:

$$
\Delta G=G_{A_{(\mathrm{aq})}^{n-}}-\frac{1}{2} G_{A_{2(\mathrm{~g})}}+n\left|e_{0}\right| U .
$$

At standard conditions and at the SHE scale is:

$$
\Delta G^{\circ}=G_{A_{(\mathrm{aq})}^{n-}}^{\circ}-\frac{1}{2} G_{A_{2(\mathrm{~g})}}^{\circ}+n\left|e_{0}\right| U_{\mathrm{SHE}}^{\circ}
$$

where $G_{A_{(\mathrm{aq})}^{n-}}^{\circ}$, is the standard solution phase free energy of the anion, $A_{(\mathrm{aq})}^{n-} . G_{A_{2(\mathrm{~g})}}^{\circ}$, is the standard gas phase free energy of the neutral species, $A_{2(\mathrm{~g})}$. The last term of equation (5), $-n\left|e_{0}\right| U$, is the free energy of the electrons participating in the reaction at an arbitrary potential scale, $n$ is the number of electrons, and $\left|e_{0}\right|$ is the elementary charge taken as positive. Equation (6) is the free energy at standard conditions, and $U_{\mathrm{SHE}}^{\circ}$, is the electrode potential of the half-cell redox reaction on the SHE scale. Therefore, the free energy of the electrons at standard conditions is $-n\left|e_{0}\right| U_{\mathrm{SHE}}^{\circ}$.

Note that at equilibrium, the change in the standard reaction free energy is equal to zero, $\Delta G^{\circ}=0$ and the standard solution phase free energy of the anion, $G_{A_{(a)}^{n-}}^{\circ}$, can be obtain from the standard gas phase free energy, $G_{A_{2(\mathrm{~g})}}^{\circ}$, and the experimentally measured equilibrium potential, $U_{\mathrm{SHE}}^{\circ}$, taken from the standard electrode potential tables $[71,72]$, as shown in equation (7)

$$
G_{A_{(\mathrm{aq})}^{n-}}^{\circ}=\frac{1}{2} G_{A_{2(\mathrm{~g})}}^{\circ}-n\left|e_{0}\right| U_{\mathrm{SHE}}^{\circ} .
$$

At a different initial concentration of the anion, we can use the Nernst equation to obtain the anion solution phase free energy at any concentration, important when comparing with experimental observations performed at non-standard state conditions, as done in reference [65] to determine the solution phase free energy of $\mathrm{Cl}^{-}$(aq) and $\mathrm{ClO}_{4}{ }^{-}$(aq). The described approach can also be used to calculate the free energy of an aqueous cation, as shown by Akhade et al [76].

\subsubsection{Half-cell redox couples with unequal number of protons} and electrons. Many electrochemical reactions involve the transfer of both protons and electrons, sometimes in unequal numbers, to or from charged species. Since we can treat the free energy of ions and the energy of electrons independently, we can use the described method twice to calculate the free energy of an ion in a reaction involving protons (or for any other number of ions). The first calculation relates the free energy of protons to hydrogen gas at equilibrium, equivalent to the CHE approach [58], and the second calculation computes the free energy of the ion of interest, as described above. This procedure can be repeated for any number of dissimilar ions in a given reaction. We can use this method with any reaction with (unequal) number of protons and electrons. Of course, the method works because at every calculation, we make use of an experimentally known equilibrium potential, as such avoiding the complicated and inaccurate calculation of the ion solvation energy.

In this method the free energy of protons is described similarly as expressed in equation (7) for the generic redox couple $\left(A_{2} / A^{n-}\right)$. In the particular case of the hydrogen half-redox reaction, $\left(H^{+} / \mathrm{H}_{2}(\mathrm{~g})\right)$, the equilibrium potential is defined to be $0 \mathrm{~V}$ on the SHE scale, and therefore the second term in equation (7) is zero, leaving the free energy of the protons equal to that of the hydrogen molecule in the gas phase as shown in equation (8) and then allowing us to use the calculated DFT energy of the $\mathrm{H}_{2}$ (g) molecules as the energy of the $H^{+}(\mathrm{aq})$, similarly as it is done within the CHE framework [58].

$$
\frac{1}{2} G_{\mathrm{H}_{2(\mathrm{~g})}}^{\circ}=G_{H_{(\mathrm{aq})}^{+}}^{\circ} .
$$

As an example, we will show in a stepwise manner how to obtain the solution phase free energy of $\mathrm{SO}_{4}{ }^{2-}$ (aq) using a half-cell redox reaction that combines a neutral species $\mathrm{SO}_{2}$ (aq) with the charged $\mathrm{SO}_{4}{ }^{2-}$ (aq) species, see equation (9). Note that the number of electrons and protons are different. The redox equation with its equilibrium potential [71] and the standard free energy are shown below:

$$
\begin{aligned}
\mathrm{SO}_{4(\mathrm{aq})}^{2-}+4 H^{+}+2 e^{-} & \rightleftharpoons \mathrm{SO}_{2(\mathrm{aq})}+2 \mathrm{H}_{2} \mathrm{O}_{(\mathrm{l})}, U_{\mathrm{SHE}}^{\circ} \\
& =0.158 \mathrm{~V} \\
\Delta G^{\circ}= & G_{\mathrm{SO}_{2(\mathrm{aq})}}^{\circ}+2 G_{\mathrm{H}_{2} \mathrm{O}(\mathrm{l})}^{\circ}-G_{\mathrm{SO}_{4(\mathrm{aq})}^{2-}}^{\circ} \\
& -4 G_{H^{+}}^{\circ}+2\left|e_{0}\right|\left(U_{\mathrm{SHE}}^{\circ}\right) .
\end{aligned}
$$

Equation (10) is equal to zero, $\Delta G^{\circ}=0$,when $U$ is equal to $U_{\mathrm{SHE}}^{\circ}$, by using equation (8), and evaluating $-n \mid e_{0} U_{\mathrm{SHE}}^{\circ}$ $=-2\left|e_{0}\right|(0.158) \mathrm{V}$ as shown in equation (11), we can calculate the standard solution phase free energy of $\mathrm{SO}_{4(\mathrm{aq})}^{2-}$ in the SHE scale, $G_{\mathrm{SO}_{4(\mathrm{aq})}^{\circ-}}^{\circ}$ as shown in equation (12)

$$
\begin{gathered}
\Delta G^{\circ}=G_{\mathrm{SO}_{2(\mathrm{aq})}}^{\circ}+2 G_{\mathrm{H}_{2} \mathrm{O}(\mathrm{l})}^{\circ}-G_{\mathrm{SO}_{4(\mathrm{aq})}^{2-}}^{\circ} \\
-2 G_{\mathrm{H}_{2(\mathrm{~g})}}^{\circ}+2 e_{0}(0.158 \mathrm{~V})=0 \\
G_{\mathrm{SO}_{4(\mathrm{aq})}^{2-}}^{\circ}=G_{\mathrm{SO}_{2(\mathrm{aq})}}^{\circ}+2 G_{\mathrm{H}_{2} \mathrm{O}(\mathrm{l})}^{\circ}-2 G_{\mathrm{H}_{2(\mathrm{~g})}}^{\circ}+2 e_{0}(0.158 \mathrm{~V})
\end{gathered}
$$

Now, the solution phase free energy of the anion can be calculated from the free energy of neutral species, that of $\mathrm{SO}_{2}(\mathrm{~g})$, $\mathrm{H}_{2}(\mathrm{~g})$ and $\mathrm{H}_{2} \mathrm{O}(\mathrm{g})$. The free energy of water is obtained from that of $\mathrm{H}_{2} \mathrm{O}(\mathrm{g})$ and corrected to that of liquid water. For $\mathrm{SO}_{2}(\mathrm{aq})$, we did not include the correction and use the energy in the gas phase (as the difference between the aqueous and gas-phase energies, based on experimental results, is almost zero $(-0.005 \mathrm{eV})$ and does not significantly change the energy (see computational methods)). 


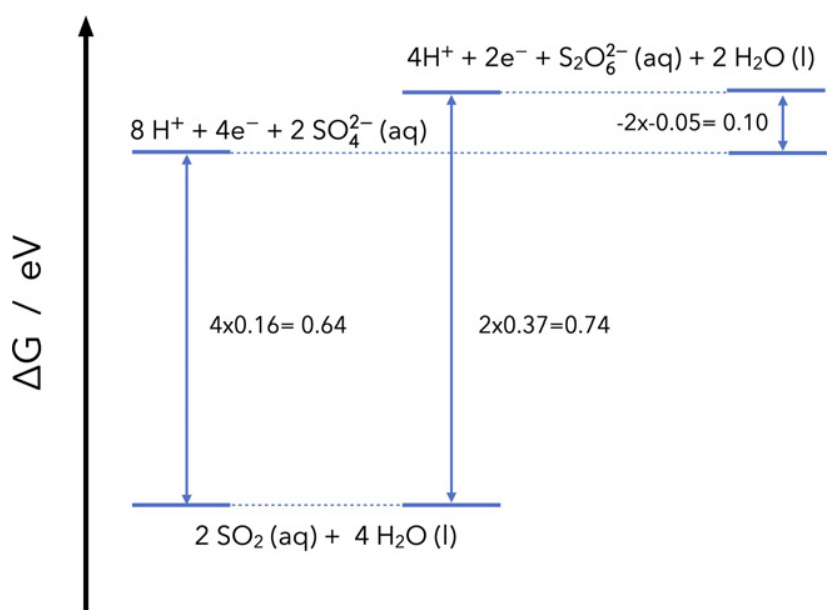

Figure 2. Illustration of electrochemical thermodynamic cycles that can be used to determine the solution phase free energy of $\mathrm{SO}_{4}{ }^{2-}$ (aq) using the standard equilibrium potentials for, $\left(\mathrm{SO}_{4}{ }^{2-}(\mathrm{aq}), \mathrm{H}^{+} / \mathrm{SO}_{2}(\mathrm{aq}), U_{\mathrm{SHE}}^{\circ}=0.158 \mathrm{~V}\right)$ [71], or by combining $\left(\mathrm{S}_{2} \mathrm{O}_{6}{ }^{2-}(\mathrm{aq}), \mathrm{H}^{+} / \mathrm{SO}_{2}(\mathrm{aq}), U_{\mathrm{SHE}}^{\circ}=0.37 \mathrm{~V}\right)[71]$, and $\left(\mathrm{SO}_{4}{ }^{2-}(\mathrm{aq})\right.$, $\left.\mathrm{H}^{+} / \mathrm{S}_{2} \mathrm{O}_{6}{ }^{2-}(\mathrm{aq}), U_{\mathrm{SHE}}^{\circ}=-0.05 \mathrm{~V}\right)[71]$.

Similarly, other redox couple reactions could be used to obtain the solution-phase free energy of $\mathrm{SO}_{4}{ }^{2-}$ (aq), as shown in figure 2, for instance the free energy of $\mathrm{SO}_{4}{ }^{2-}(\mathrm{aq})$, can also be determined from the equilibrium potentials of $\left(\mathrm{S}_{2} \mathrm{O}_{6}{ }^{2-}(\mathrm{aq})\right.$, $\left.\mathrm{H}^{+} / \mathrm{SO}_{2}(\mathrm{aq}), U_{\mathrm{SHE}}^{\circ}=0.37 \mathrm{~V}\right)$ to determine the energy of $\mathrm{S}_{2} \mathrm{O}_{6}{ }^{2-}$ (aq) and then followed by $\left(\mathrm{SO}_{4}{ }^{2-}(\mathrm{aq}), \mathrm{H}^{+} / \mathrm{S}_{2} \mathrm{O}_{6}{ }^{2-}(\mathrm{aq})\right.$, $\left.U_{\mathrm{SHE}}^{\circ}=-0.05 \mathrm{~V}\right)$ to then determine the solution phase free energy of $\mathrm{SO}_{4}{ }^{2-}$ (aq) [71].

\subsection{Equilibrium adsorption energies and adsorption potentials}

The solution phase free energy of an ion is important in many areas of research, and is particularly important for surface electrochemistry and (electro)catalysis, as the solution phase free energy of an ion can be used to calculate adsorption thermodynamics, and is necessary for comparing the adsorption strength between different species/adsorbates. These adsorption thermodynamics can be calculated relative to a neutral, gas phase species such as $\mathrm{Cl}_{2}(\mathrm{~g})$ instead of $\mathrm{Cl}^{-}(\mathrm{aq})$, but this prohibits comparing adsorption strength from solution between different adsorbates (for example, $\mathrm{Cl}^{*}$ to $\mathrm{Br}^{*}$ ) as this comparison will require a correction of the gas-phase dissociation energy, ionization energy, and solvation energy for each adsorbate. It is important to be able to compare the adsorption strength between adsorbates as it allows the state, structure, and composition of the surface to be determined, for instance through a surface phase diagram.

In this section we will show how to calculate the adsorption energy of an anion on any given surface site using the solution phase free energy obtained using the method described here. The adsorption thermodynamics are calculated following the reaction given in equation (13), where $A_{(\text {aq) }}^{n-}$ represents a generic anion, $\left(^{*}\right)$ a bare surface site, and $A^{*}$ the adsorbed anion.

$$
A_{(\mathrm{aq})}^{n-}+* \rightarrow A^{*}+n e^{-}
$$

A similar reaction can be written for cation adsorption, with the electron written as a reactant instead of a product. Based on equation (13), we can write the change in free energy upon adsorption, shown in equation (14) (again, a similar equation can be written for cation adsorption):

$$
\Delta G^{\mathrm{ads}}=G_{A^{*}}-G_{*}-G_{A_{(\mathrm{aq})}^{n-}}-n\left|e_{0}\right| U_{\mathrm{SHE}}
$$

where $G_{A^{*}}$ is the free energy of the adsorbed species, $G_{*}$ the free energy of the bare surface, $G_{A_{\text {(aq) }}^{n-}}$ the free energy of the solution phase anion, and $-n\left|e_{0}\right| U_{\mathrm{SHE}}$ the free energy of the electrons transferred in the reaction at potential $U_{\mathrm{SHE}}$, and the final adsorption energy can be shifted linearly with this term at an applied bias of interest to build, for instance, energy vs potential diagrams. Combining the CHE [58] approach with this method we can add a term to equation (14) to consider the change in dipole moment induced by the adsorption of the charge species $\left({ }^{*} A\right)$ on the surface $\left({ }^{*}\right), \Delta \mu^{\text {ads }}=\left(\mu_{* A}-\mu_{*}\right)$, and an additional term, $\left(U_{\mathrm{SHE}}-U_{\mathrm{PZC}} / d\right)$, to account for the dipole interaction with the electrode-electrolyte electric field. $d$ is $\sim 3.0 \AA$ based on the Helmholtz approximation of the double layer [58], and we get equation (15)

$$
\begin{aligned}
\Delta G_{* A}^{\mathrm{ads}}= & G_{A^{*}}-G_{*}-G_{A_{(\mathrm{aq})}^{n-}}-n\left|e_{0}\right| U_{\mathrm{SHE}} \\
& +\Delta \mu^{\mathrm{ads}} \frac{\left(U_{\mathrm{SHE}}-U_{\mathrm{PZC}}\right)}{d}
\end{aligned}
$$

The potential of zero charge, $U_{\mathrm{PZC}}$, is taken as that experimentally measured in the SHE scale [103]. Approximating the $U_{\mathrm{PZC}}$ to $0 U_{\mathrm{SHE}}$ does not significantly change the absolute adsorption potentials, see table S3 (https://stacks.iop.org/JPCM/33/204001/mmedia). This equation can then be solved for the equilibrium adsorption potential, $U_{\mathrm{ads}, \mathrm{SHE}}^{\circ}$, which represents the potential where adsorption becomes favorable (when $\Delta G^{\text {ads }}=0$ ), shown in equation (16)

$$
U_{\mathrm{ads}, \mathrm{SHE}}^{\circ}=\frac{G_{* A}-G_{A^{-}}(\mathrm{aq})-G_{*}-\frac{\Delta \mu^{\mathrm{ads}}}{d} U_{\mathrm{PZC}}}{n\left|e_{0}\right|-\frac{\Delta \mu^{\mathrm{ads}}}{d}} .
$$

The potential scale on which this equilibrium adsorption potential sits depends on the methodology used to calculate the free energy of the ion in solution. Here, the standard hydrogen electrode scale is used. The free energy of the adsorbed species $\mathrm{G}_{A^{*}}$, is calculated following equation (17):

$$
G_{A^{*}}=E_{\mathrm{DFT}}+\mathrm{ZPVE}-\mathrm{TS}_{\mathrm{vib}}
$$

where $E_{\mathrm{DFT}}$ is the $0 \mathrm{~K}$ DFT energy of the adsorbate on the surface, the ZPVE is the zero-point vibrational energy, and $S_{\text {vib }}$ is the vibrational entropy of the adsorbate. The free energy of the bare surface, $G_{*}$, is taken simply as the DFT energy at $0 \mathrm{~K}$ given that vibrational energy/entropy of the surface is not significantly perturbed by the adsorbate. 


\section{Results and discussion}

\subsection{Applications of the method in electrocatalysis}

To illustrate the use of this method in calculating relative adsorption strengths, we have calculated the adsorption free energy at low coverage (1/9 ML) of iodide, bromide, chloride, and sulfate on $\mathrm{Pt}(111)$ and $\mathrm{Au}(111)$ and hydroxide on $\mathrm{Pt}(111)$. For comparison, we have also calculated the adsorption free energy of $\mathrm{Ag}$ on $\mathrm{Pt}(111)$. From these adsorption free energies, we have calculated the equilibrium adsorption potential, the potential at which adsorption (at this coverage) becomes favorable, and plotted this against the experimentally measured adsorption potential. This is shown in figure 3(a).

From figure 3(a), it is clear that we can capture the relative trend in adsorption strength between each of these species, with the trend between the anions following $\mathrm{I}^{*}>\mathrm{Br}^{*}>\mathrm{Cl}^{*}$ $>\mathrm{SO}_{4}{ }^{*}>\mathrm{OH}^{*}$ across both surfaces. It is also apparent that all of the adsorbates bind less strongly on $\mathrm{Au}(111)$ than on $\operatorname{Pt}(111)$. The reason for this can be rationalized in terms of a more repulsive interaction between the adsorbates outer $\mathrm{p}$ shells and the expanded d band of $\mathrm{Au}(111)$, compared to $\mathrm{Pt}(111)$, due to relativistic effects being more predominant on $\mathrm{Au}(111)$ [104-106]. Furthermore, the d band of $\mathrm{Au}(111)$ is more occupied than $\operatorname{Pt}(111)$ [107]. This repulsive interaction also results in a longer bond length between the ions and the surface for ions adsorbed on $\mathrm{Au}(111)$ than on $\mathrm{Pt}(111)$, see table S1. Of course, these trends were already known from experiment, [108, 109] and agree well with prior computational calculations [105].

We also examined the change in work function and the partial charges on the adsorbates with a Bader charge analysis, summarized in table $\mathrm{S} 1$. We note that the analysis which includes solvation $\left(\mathrm{SO}_{4}{ }^{*}\right.$-sol) considers only the change in work function associated with the single adsorbed water structures considered for the reactant $\left(6 \mathrm{H}_{2} \mathrm{O}^{*}\right)$ and product $\left(\mathrm{SO}_{4}{ }^{*}\right.$ $+4 \mathrm{H}_{2} \mathrm{O}^{*}$ ) states. Our calculations follow the general trends found previously with DFT, see Groß et al [110-112], Pašti et al [107, 113, 114] and Illas et al [105]. For Pt(111) we find a decrease in work function induced by the adsorption of $\mathrm{Cl}$, $\mathrm{Br}$, and $\mathrm{I}$, and an increase induced by the adsorption of $\mathrm{SO}_{4}$. In the case of $\mathrm{Au}(111)$, we see an increase in work function induced by the adsorption of $\mathrm{Cl}, \mathrm{Br}$ and $\mathrm{SO}_{4}$ and a decrease induced by the adsorption of $\mathrm{I}$.

Based on the Bader charge analysis, the adsorbates which retain more negative charge also induce a larger dipole moment (table S1), and therefore they would benefit from solvation near the electrode surface to stabilize their energy. The general trend for large to small induced dipole moment on both $\mathrm{Pt}(111)$ and $\mathrm{Au}(111)$ follows $\mathrm{SO}_{4}>\mathrm{Cl}>\mathrm{Br}>\mathrm{I}$. The work function of $\mathrm{Au}(111)$ is smaller than that of $\operatorname{Pt}(111)$ [115]. This means that it is easier to remove electrons from $\mathrm{Au}(111)$ than $\mathrm{Pt}(111)$, and therefore the electronegative adsorbates on $\mathrm{Au}(111)$ will retain more negative charge than when adsorbed on $\mathrm{Pt}(111)$. The character of the halide bond on both $\mathrm{Pt}(111)$ and $\mathrm{Au}(111)$ has been conceptualized to be covalent in nature $[112,116]$, however we can say that between the two, the bonding on $\mathrm{Au}(111)$ is slightly more ionic than on $\operatorname{Pt}(111)$, especially for
$\mathrm{Cl}, \mathrm{Br}$ and $\mathrm{SO}_{4}$. In general, adsorbates that show higher charge separation tend to be more ionic in character [117], but that is not always the case (as for instance $\mathrm{Cl}$ on $\mathrm{Cu}(111)$, [118]). Additional studies of electronic structure would be necessary to further investigate this.

The important result from figure 3(a) is that by using the method of determining the free energy of each ion in the solution phase, at the same potential scale, we can reproduce the trends in adsorption potentials from DFT. We can now be confident in applying this method to understand more complex phenomena.

In general, we see good agreement between DFT and experiment when we include near-surface solvation for not only the trend in adsorption strength between adsorbates, but also the absolute value of the adsorption potentials. We can use figures 3(a) and (b) to make a few important points about this accuracy.

First, we note that we expect the calculated adsorption potential to be exchange-correlation functional dependent; the exact magnitude of the adsorption energy will vary with functional. If there is a significant difference in the van der Waals contribution to binding for these adsorbates between $\operatorname{Pt}(111)$ and $\mathrm{Au}(111)$, this could cause an additional dependence on functional, as traditional functionals poorly capture van der Waals interactions. However, we expect the trend between the adsorbates, differences between adsorption on $\mathrm{Au}(111)$ and $\mathrm{Pt}(111)$ (assuming the van der Waals contribution to binding is small), and the effect of near-surface solvation, to be less dependent on the chosen functional.

Second, it is interesting to see that by including only a few explicit water molecules hydrogen-bonded to the adsorbate, the adsorption potentials for $\mathrm{SO}_{4}{ }^{*}$ on both $\mathrm{Pt}(111)$ and $\mathrm{Au}(111)$ as well as for $\mathrm{OH}^{*}$ on $\mathrm{Pt}(111)$ are brought much closer to those measured experimentally (figure 3(b)), compared to figure 3(a), where they are without solvation and therefore further from the experimental results. This suggests that the influence of the rest of the water in the electrochemical environment, the second and third solvation shells of the adsorbate, might not further influence the stabilization of the adsorbate. Prior work by Calle-Vallejo et al $[119,120]$ and Janik et al [121] suggests that for many adsorbates, there is a threshold number of explicit water molecules that will stabilize the energy of the adsorbate, and above that number, there is no significant impact. A wide variety of other methods for solvating the surface (implicit solvation, explicit solvation with classical or ab initio molecular dynamics; for example) can be used in combination with the method we describe to calculate the free energy of the ion in solution, to further probe the effects of near-surface solvation on the adsorption energetics.

Third, it appears that the adsorption potentials on $\mathrm{Au}(111)$ are consistently underpredicted relative to experiment (at least for $\mathrm{I}^{*}, \mathrm{Br}^{*}$, and $\mathrm{Cl}^{*}$ ), whereas this is not the case for $\mathrm{Pt}(111)$. Table S1 shows that the anions retain more negative charge (and create a larger change in surface-normal dipole moment on adsorption) on $\mathrm{Au}(111)$ than on $\mathrm{Pt}(111)$. We have included the dipole correction to the adsorption potential as calculated in equation (16), but this does not lead to a significant change in adsorption potential (table S3), and so this alone cannot 

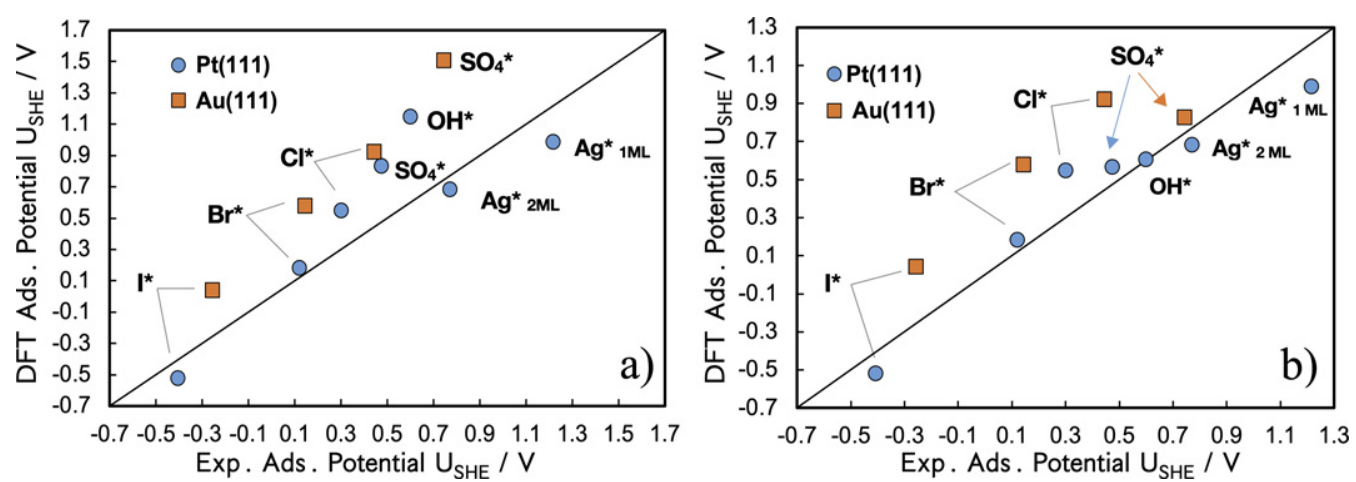

Figures 3. (a), (b) DFT simulated and experimentally measured equilibrium adsorption potential $[108,109,122]$ of $\mathrm{I}^{*}, \mathrm{Br}^{*}, \mathrm{Cl}^{*}$, and $\mathrm{SO}_{4}{ }^{*}$ on $\mathrm{Pt}(111)$ and $\mathrm{Au}(111)$ as well as $\mathrm{OH}^{*}$ and the first and second MLs of $\mathrm{Ag}^{*}$ on $\mathrm{Pt}(111)$. All potentials are simulated/measured at low coverage (1/9 Ml), except for $\mathrm{Ag}^{*}$ on $\mathrm{Pt}(111)$ (for which the coverage is 1 and $2 \mathrm{Ml}$ ). In (b), the adsorption potentials calculated for $\mathrm{OH}^{*} \mathrm{on}$ $\mathrm{Pt}(111)$ and $\mathrm{SO}_{4}{ }^{*}$ on $\mathrm{Pt}(111)$ and $\mathrm{Au}(111)$ include the effect of near-surface solvation, approximated by including co-adsorbed water molecules. Table $\mathrm{S} 2$ shows the calculated and experimentally measured adsorption potentials.

explain the difference in 'accuracy' between $\mathrm{Au}(111)$ and Pt(111). We might expect however, that the effect of nearsurface solvation depends, at least in part, on the magnitude of the surface-normal dipole moment. As the halides retain more charge and generate a more positive surface normal dipole moment upon adsorption on $\mathrm{Au}(111)$ than on $\mathrm{Pt}(111)$, we expect the effect of near-surface solvation on the adsorption of the halides, which we did not consider, to be larger on $\mathrm{Au}(111)$ than on $\operatorname{Pt}(111)$. In support of this idea, we can see that figure 3(a), where near-surface solvation is neglected (for all adsorbates), the calculated adsorption potential is equally far from the $y=x$ line for both $\mathrm{Pt}(111)$ and $\mathrm{Au}(111)$ for adsorbates which generate a more positive surface-normal dipole moment $\left(\mathrm{Cl}^{*}, \mathrm{SO}_{4}{ }^{*}\right)$. Additionally, we find the magnitude of the effect of solvation on the adsorption of $\mathrm{SO}_{4}{ }^{*}$ (shifts adsorption potential by $-0.27 \mathrm{~V}$ on $\mathrm{Pt}(111)$ and $-0.68 \mathrm{~V}$ on $\mathrm{Au}(111))$ is proportional to the change in surface-normal dipole moment $(0.47$ $\mathrm{e} \AA$ on $\mathrm{Pt}(111), 0.82 \mathrm{e} \AA$ on $\mathrm{Au}(111))$. We note that additional differences between $\mathrm{Pt}(111)$ and $\mathrm{Au}(111)$ could be due to a difference in the contribution of van der Waals interactions, which traditional exchange-correlation functionals poorly describe, as well as experimental factors; the experimentally measured potentials for anion adsorption on $\mathrm{Au}(111)$ were measured relative to the saturated calomel electrode, its potential on an SHE scale had to be assumed to shift these potentials to the same scale as those measured on $\mathrm{Pt}(111)$.

Lastly, the adsorption of some of the ions competes with that of other species (for example, $\mathrm{I}^{*}$ on $\mathrm{Pt}(111)$ with $\mathrm{H}^{*}$, and $\mathrm{Ag}^{*}$ on $\mathrm{Pt}(111)$ with $\mathrm{SO}_{4}{ }^{*}$ ), which would affect the measured adsorption potential; we have not considered this effect.

The preceding discussion makes it clear that the accuracy of the calculated adsorption potentials depends on a variety of factors including (i) the choice of exchange correlation functional (which influences both the energy of the reference gas-phase molecule to calculate the free energy of the ion in solution and the adsorption energy), (ii) the inclusion of near-surface solvation effects, (iii) co-adsorption, and (iv) the accuracy of the experimentally measured adsorption potential (including the choice and stability of the reference electrode). We discuss these points here as they are important to understand how to model ion adsorption in the electrochemical environment, but each requires further study. Therefore, this work is not intended as an evaluation of the accuracy of the method we have described here for calculating the free energy of solution-phase ions, only an example of its usefulness and simplicity.

\section{Conclusions}

In this paper we have revised and illustrated a simple method that facilitates the calculation of solution phase free energies of ions, eliminating the need to model solvation of the ions in bulk solution, and showed its importance by calculating adsorption potentials of different ions on the same potential scale. This is achieved by using an experimentally measured equilibrium potential to calculate the free energy of the ion in solution from a neutral gas-phase or solid-phase species. This method shows how the electrons and protons can be numerically arranged separately allowing any half-cell redox reaction to be used.

We apply this method to examine the adsorption of a variety of different ions on $\mathrm{Pt}(111)$ and $\mathrm{Au}(111)$ and show the trend in adsorption strength matches the trend seen experimentally. This method is computationally efficient and its accuracy in terms of the energetics of the solution phase charged species is only limited by how well DFT can model neutral gas-phase species and by the accuracy of the experimentally measured equilibrium potential of the reaction which connects the ion of interest to the neutral gas or solid-phase species. However, the accuracy of the calculated ion adsorption potential then, not only depends on the previous limitations but also by how well DFT can capture the effects of near-surface solvation, especially for adsorbates which induce a large surface-normal dipole moment, and the effects of a near-surface electric field.

The method used here is not new, however, we hope that by describing the methodology in detail and illustrating its usefulness, it will see more widespread use, such that the thermodynamics and kinetics of electrochemical and electrocatalytic reactions involving ions other than protons, will be more frequently simulated with DFT. Such a method is necessary, for example, to examine the composition of a catalyst surface 
in the electrochemical environment (surface phase diagram), competition in adsorption between species under reaction conditions, and the stability of an electrode or catalyst surface with respect to dissolution or (re)deposition; all examples at the forefront of computational electrocatalysis.

\section{Acknowledgments}

Laura P Granda-Marulanda acknowledges funding from the European Union through the A-leaf project (732840A-LEAF). Ian $\mathrm{T}$ McCrum received funding from the European Union's Horizon 2020 Research and Innovation Program under the Marie Skłodowska-Curie Grant agreement No. 707404. The use of SURFsara supercomputing facilities is sponsored by NWO Physical Sciences with financial support by NWO (Netherlands Organization for Scientific Research).

\section{Data availability statement}

The data that support the findings of this study are available upon reasonable request from the authors.

\section{ORCID iDs}

Marc T M Koper (1) https://orcid.org/0000-0001-6777-4594

\section{References}

[1] Hori Y, Koga O, Yamazaki H and Matsuo T 1995 Infrared spectroscopy of adsorbed $\mathrm{CO}$ and intermediate species in electrochemical reduction of $\mathrm{CO}_{2}$ to hydrocarbons on a $\mathrm{Cu}$ electrode Electrochim. Acta 40 2617-22

[2] Osawa M 1997 Dynamic processes in electrochemical reactions studied by surface-enhanced infrared absorption spectroscopy (SEIRAS) Bull. Chem. Soc. Japan 70 2861-80

[3] Heinen M, Chen Y X, Jusys Z and Behm R J 2007 In situ ATR-FTIRS coupled with on-line DEMS under controlled mass transport conditions-a novel tool for electrocatalytic reaction studies Electrochim. Acta $\mathbf{5 2}$ 5634-43

[4] Neto A O, Nandenha J, Assumpção M H M T, Linardi M, Spinacé E V and de Souza R F B 2013 In situ spectroscopy studies of ethanol oxidation reaction using a single fuel cell/ATR-FTIR setup Int. J. Hydrogen Energy 38 10585-91

[5] Pander J E, Baruch M F and Bocarsly A B 2016 Probing the mechanism of aqueous $\mathrm{CO}_{2}$ reduction on posttransition-metal electrodes using ATR-IR spectroelectrochemistry ACS Catal. 6 7824-33

[6] Wain A J and O'Connell M A 2017 Advances in surfaceenhanced vibrational spectroscopy at electrochemical interfaces Adv. Phys.: X 2 188-209

[7] Perales-Rondon J V, Hernandez S, Martin-Yerga D, FanjulBolado P, Heras A and Colina A 2018 Electrochemical surface oxidation enhanced Raman scattering Electrochim. Acta 282 377-83

[8] Baricuatro J H, Kim Y-G, Korzeniewski C L and Soriaga M P 2020 Tracking the prelude of the electroreduction of carbon monoxide via its interaction with $\mathrm{Cu}(100)$ : studies by operando scanning tunneling microscopy and infrared spectroscopy Catal. Today 358 210-4

[9] Zhu Y, Wang J, Chu H, Chu Y-C and Chen H M 2020 In situ/operando studies for designing next-generation electrocatalysts ACS Energy Lett. 5 1281-91
[10] Greeley J and Mavrikakis M 2004 Alloy catalysts designed from first principles Nat. Mater. 3 810-5

[11] Greeley J, Jaramillo T F, Bonde J, Chorkendorff I and Nørskov J K 2006 Computational high-throughput screening of electrocatalytic materials for hydrogen evolution Nat. Mater. 5 909-13

[12] Magnussen O M and Groß A 2019 Toward an atomic-scale understanding of electrochemical interface structure and dynamics J. Am. Chem. Soc. 141 4777-90

[13] Xin H and Linic S 2010 Communications: exceptions to the d-band model of chemisorption on metal surfaces: the dominant role of repulsion between adsorbate states and metal d-states J. Chem. Phys. 132221101

[14] Norskov J K, Abild-Pedersen F, Studt F and Bligaard T 2011 Density functional theory in surface chemistry and catalysis Proc. Natl Acad. Sci. 108 937-43

[15] Diaz-Morales O, Ledezma-Yanez I, Koper M T M and CalleVallejo F 2015 Guidelines for the rational design of Nibased double hydroxide electrocatalysts for the oxygen evolution reaction ACS Catal. 5 5380-7

[16] Sakong S and Groß A 2018 The electric double layer at metalwater interfaces revisited based on a charge polarization scheme J. Chem. Phys. 149084705

[17] Schnur S and Groß A 2011 Challenges in the first-principles description of reactions in electrocatalysis Catal. Today 165 129-37

[18] Rossmeisl J, Skúlason E, Björketun M E, Tripkovic V and Nørskov J K 2008 Modeling the electrified solid-liquid interface Chem. Phys. Lett. 466 68-71

[19] Cohen A J, Mori-Sánchez P and Yang W 2008 Insights into current limitations of density functional theory Science $\mathbf{3 2 1}$ $792-4$

[20] Lozovoi A Y, Alavi A, Kohanoff J and Lynden-Bell R M 2001 $A b$ initio simulation of charged slabs at constant chemical potential J. Chem. Phys. 115 1661-9

[21] Filhol J-S and Neurock M 2006 Elucidation of the electrochemical activation of water over Pd by first principles Angew. Chem., Int. Ed. 45 402-6

[22] Taylor C D, Wasileski S A, Filhol J-S and Neurock M 2006 First principles reaction modeling of the electrochemical interface: consideration and calculation of a tunable surface potential from atomic and electronic structure Phys. Rev. B 73165402

[23] Gauthier J A, Chen L D, Bajdich M and Chan K 2020 Implications of the fractional charge of hydroxide at the electrochemical interface Phys. Chem. Chem. Phys. 22 6964-9

[24] Tölle J, Gomes A S P, Ramos P and Pavanello M 2019 Charged-cell periodic DFT simulations via an impurity model based on density embedding: application to the ionization potential of liquid water Int. J. Quantum Chem. 119 e25801

[25] Schnur S and Groß A 2009 Properties of metal-water interfaces studied from first principles New J. Phys. 11125003

[26] Desai S K, Pallassana V and Neurock M 2001 A periodic density functional theory analysis of the effect of water molecules on deprotonation of acetic acid over $\operatorname{Pd}(111) \mathrm{J}$. Phys. Chem. B 105 9171-82

[27] Gauthier J A, Dickens C F, Chen L D, Doyle A D and Nørskov J K 2017 Solvation effects for oxygen evolution reaction catalysis on $\mathrm{IrO}_{2}(110)$ J. Phys. Chem. C 121 11455-63

[28] Kimmel G A, Matthiesen J, Baer M, Mundy C J, Petrik N G, Smith R S, Dohnálek Z and Kay B D 2009 J. Am. Chem. Soc. 131 12838-44

[29] Gunathunge C M, Ovalle V J, Li Y, Janik M J and Waegele M M 2018 Existence of an electrochemically inert CO population on $\mathrm{Cu}$ electrodes in alkaline $\mathrm{pH}$ ACS Catal. 8 7507-16 
[30] Tripkovic V 2017 Thermodynamic assessment of the oxygen reduction activity in aqueous solutions Phys. Chem. Chem. Phys. 19 29381-8

[31] Shan N and Liu B 2019 Elucidating molecular interactions in glycerol adsorption at the metal-water interface with density functional theory Langmuir 35 4791-805

[32] Ringe S, Oberhofer H, Hille C, Matera S and Reuter K 2016 Function-space-based solution scheme for the sizemodified Poisson-Boltzmann equation in full-potential DFT J. Chem. Theor. Comput. 12 4052-66

[33] Mathew K, Sundararaman R, Letchworth-Weaver K, Arias T A and Hennig R G 2014 Implicit solvation model for densityfunctional study of nanocrystal surfaces and reaction pathways J. Chem. Phys. 140084106

[34] Schwarz K A, Sundararaman R, Moffat T P and Allison T C 2015 Formic acid oxidation on platinum: a simple mechanistic study Phys. Chem. Chem. Phys. 17 20805-13

[35] Sakong S and Groß A 2016 The importance of the electrochemical environment in the electro-oxidation of methanol on Pt(111) ACS Catal. 6 5575-86

[36] Weitzner S E, Akhade S A, Varley J B, Wood B C, Otani M, Baker S E and Duoss E B 2020 Toward engineering of solution microenvironments for the $\mathrm{CO}_{2}$ reduction reaction: unraveling $\mathrm{pH}$ and voltage effects from a combined density-functional-continuum theory J. Phys. Chem. Lett. 11 4113-8

[37] Qiao C, Zhang J, Jiang P, Zhao S, Song X and Yu J 2020 A molecular approach for predicting phase diagrams of ternary aqueous saline solutions Chem. Eng. Sci. 211115278

[38] Brancato G, Rega N and Barone V 2008 A hybrid explicit/implicit solvation method for first-principle molecular dynamics simulations J. Chem. Phys. 128144501

[39] Sakong S, Naderian M, Mathew K, Hennig R G and Groß A 2015 Density functional theory study of the electrochemical interface between a Pt electrode and an aqueous electrolyte using an implicit solvent method J. Chem. Phys. 142234107

[40] Ge X, Wang J, Zhang Z, Wang X and Chen M 2015 Thermodynamic modeling of electrolyte solutions by a hybrid ioninteraction and solvation (HIS) model Calphad 48 79-88

[41] Spohr E 1989 Computer simulation of the water/platinum interface J. Phys. Chem. 93 6171-80

[42] Li X and Ågren H 2015 Molecular dynamics simulations using a capacitance-polarizability force field J. Phys. Chem. C 119 19430-7

[43] Steinmann S N, Ferreira De Morais R, Götz A W, FleuratLessard P, Iannuzzi M, Sautet P and Michel C 2018 Force field for water over $\mathrm{Pt}(111)$ : development, assessment, and comparison J. Chem. Theor. Comput. 14 3238-51

[44] Sundararaman R and Schwarz K 2017 Evaluating continuum solvation models for the electrode-electrolyte interface: challenges and strategies for improvement J. Chem. Phys. 146084111

[45] Steinmann S N, Sautet P and Michel C 2016 Solvation free energies for periodic surfaces: comparison of implicit and explicit solvation models Phys. Chem. Chem. Phys. 18 31850-61

[46] Gauthier J A, Ringe S, Dickens C F, Garza A J, Bell A T, Head-Gordon M, Nørskov J K and Chan K 2019 Challenges in modeling electrochemical reaction energetics with polarizable continuum models ACS Catal. 9 920-31

[47] Marenich A V, Cramer C J and Truhlar D G 2009 Universal solvation model based on solute electron density and on a continuum model of the solvent defined by the bulk dielectric constant and atomic surface tensions J. Phys. Chem. B 113 6378-96

[48] Kelly C P, Cramer C J and Truhlar D G 2006 Aqueous solvation free energies of ions and ion-water clusters based on an accurate value for the absolute aqueous solvation free energy of the proton J. Phys. Chem. B 110 16066-81
[49] Marković Z, Tošović J, Milenković D and Marković S 2016 Revisiting the solvation enthalpies and free energies of the proton and electron in various solvents Comput. Theor. Chem. 1077 11-7

[50] Malloum A, Fifen J J and Conradie J 2018 Solvation energies of the proton in methanol revisited and temperature effects Phys. Chem. Chem. Phys. 20 29184-206

[51] Zhan C-G and Dixon D A 2002 First-principles determination of the absolute hydration free energy of the hydroxide ion $J$. Phys. Chem. A 106 9737-44

[52] Bryantsev V S, Diallo M S and Goddard W A III 2008 Calculation of solvation free energies of charged solutes using mixed cluster/continuum models J. Phys. Chem. B 112 9709-19

[53] Dupont C, Andreussi O and Marzari N 2013 Self-consistent continuum solvation (SCCS): the case of charged systems J. Chem. Phys. 139214110

[54] Pliego J R 2003 Thermodynamic cycles and the calculation of $\mathrm{pK}_{\mathrm{a}}$ Chem. Phys. Lett. 367 145-9

[55] Ho J 2014 Are thermodynamic cycles necessary for continuum solvent calculation of $\mathrm{pK}_{\mathrm{a}}$ 's and reduction potentials? Phys. Chem. Chem. Phys. 17 2859-68

[56] Wang C, Ren P and Luo R 2017 Ionic solution: what goes right and wrong with continuum solvation modeling J. Phys. Chem. B 121 11169-79

[57] Stein C J, Herbert J M and Head-Gordon M 2019 The Poisson-Boltzmann model for implicit solvation of electrolyte solutions: quantum chemical implementation and assessment via Sechenov coefficients J. Chem. Phys. 151224111

[58] Nørskov J K, Rossmeisl J, Logadottir A, Lindqvist L, Kitchin J R, Bligaard T and Jónsson H 2004 Origin of the overpotential for oxygen reduction at a fuel-cell cathode $J$. Phys. Chem. B 108 17886-92

[59] Calle-Vallejo F, Huang M, Henry J B, Koper M T M and Bandarenka A S 2013 Theoretical design and experimental implementation of $\mathrm{Ag} / \mathrm{Au}$ electrodes for the electrochemical reduction of nitrate Phys. Chem. Chem. Phys. 15 3196-202

[60] McCrum I T, Akhade S A and Janik M J 2015 Electrochemical specific adsorption of halides on $\mathrm{Cu} 111,100$, and 211: a density functional theory study Electrochim. Acta $\mathbf{1 7 3}$ 302-9

[61] Yeh K-Y, Restaino N A, Esopi M R, Maranas J K and Janik M J 2013 The adsorption of bisulfate and sulfate anions over a Pt(111) electrode: a first principle study of adsorption configurations, vibrational frequencies and linear sweep voltammogram simulations Catal. Today 202 20-35

[62] Trasatti S 1986 The absolute electrode potential: an explanatory note (recommendations 1986) Pure Appl. Chem. 58 955-66

[63] Hansen H A, Man I C, Studt F, Abild-Pedersen F, Bligaard T and Rossmeisl J 2009 Electrochemical chlorine evolution at rutile oxide (110) surfaces Phys. Chem. Chem. Phys. 12 283-90

[64] Gossenberger F, Roman T and Groß A 2016 Hydrogen and halide co-adsorption on $\mathrm{Pt}(111)$ in an electrochemical environment: a computational perspective Electrochim. Acta $216152-9$

[65] Bondarenko A S, Stephens I E L, Hansen H A, Pérez-Alonso F J, Tripkovic V, Johansson T P, Rossmeisl J, Nørskov J K and Chorkendorff I 2011 The Pt(111)/electrolyte interface under oxygen reduction reaction conditions: an electrochemical impedance spectroscopy study Langmuir 27 2058-66

[66] Gossenberger F, Juarez F and Groß A 2020 Sulfate, bisulfate, and hydrogen Co-adsorption on $\mathrm{Pt}(111)$ and $\mathrm{Au}(111)$ in an electrochemical environment Front. Chem. 8634

[67] Harima Y 1988 Standard potential and chemical solvation energy of an electron in ethylenediamine J. Electroanal. Chem. Interfacial Electrochem. 252 53-60 
[68] Marenich A V, Ho J, Coote M L, Cramer C J and Truhlar D G 2014 Computational electrochemistry: prediction of liquid-phase reduction potentials Phys. Chem. Chem. Phys. 16 15068-106

[69] Göttle A J and Koper M T M 2017 Proton-coupled electron transfer in the electrocatalysis of $\mathrm{CO}_{2}$ reduction: prediction of sequential vs concerted pathways using DFT Chem. Sci. $8458-65$

[70] Kepp K P 2018 Thermochemically consistent free energies of hydration for di- and trivalent metal ions J. Phys. Chem. A $1227464-71$

[71] Bratsch S G 1989 Standard electrode potentials and temperature coefficients in water at $298.15 \mathrm{~K}$ J. Phys. Chem. Ref. Data 18 1-21

[72] Lide D R 2004 CRC Handbook of Chemistry and Physics 85th edn (Boca Raton, FL: CRC Press)

[73] Strmcnik D, Kodama K, van der Vliet D, Greeley J, Stamenkovic V R and Marković N M 2009 The role of noncovalent interactions in electrocatalytic fuel-cell reactions on platinum Nat. Chem. $1466-72$

[74] Stoffelsma C, Rodriguez P, Garcia G, Garcia-Araez N, Strmcnik D, Marković N M and Koper M T M 2010 Promotion of the oxidation of carbon monoxide at stepped platinum single-crystal electrodes in alkaline media by lithium and beryllium cations J. Am. Chem. Soc. 132 16127-33

[75] Colic V, Pohl M D, Scieszka D and Bandarenka A S 2016 Influence of the electrolyte composition on the activity and selectivity of electrocatalytic centers Catal. Today $\mathbf{2 6 2}$ $24-35$

[76] Akhade S A, McCrum I T and Janik M J 2016 The impact of specifically adsorbed ions on the coppercatalyzed electroreduction of $\mathrm{CO}_{2}$ J. Electrochem. Soc. 163 F477

[77] McCrum I T and Janik M J 2016 First principles simulations of cyclic voltammograms on stepped $\mathrm{Pt}(553)$ and $\mathrm{Pt}(533)$ electrode surfaces ChemElectroChem 3 1609-17

[78] Ringe S, Clark E L, Resasco J, Walton A, Seger B, Bell A T and Chan K 2019 Understanding cation effects in electrochemical $\mathrm{CO}_{2}$ reduction Energy Environ. Sci. 12 3001-14

[79] Waegele M M, Gunathunge C M, Li J and Li X 2019 How cations affect the electric double layer and the rates and selectivity of electrocatalytic processes J. Chem. Phys. 151 160902

[80] Gauthier J A, Fields M, Bajdich M, Chen L D, Sandberg R B, Chan K and Nørskov J K 2019 Facile electron transfer to $\mathrm{CO}_{2}$ during adsorption at the metal|solution interface $J$. Phys. Chem. C 123 29278-83

[81] Kristoffersen H H, Chan K, Vegge T and Hansen H A 2020 Energy-entropy competition in cation-hydroxyl interactions at the liquid water-Pt(111) interface Chem. Commun. 56 427-30

[82] Kresse G and Furthmüller J 1996 Efficient iterative schemes for ab initio total-energy calculations using a plane-wave basis set Phys. Rev. B 54 11169-86

[83] Kresse G and Furthmüller J 1996 Efficiency of ab initio total energy calculations for metals and semiconductors using a plane-wave basis set Comput. Mater. Sci. 6 15-50

[84] Kresse G 1995 Ab initio molecular dynamics for liquid metals J. Non-Cryst. Solids 192-193 222-9

[85] Blöchl P E 1994 Projector augmented-wave method Phys. Rev. B 50 17953-79

[86] Kresse G and Joubert D 1999 From ultrasoft pseudopotentials to the projector augmented-wave method Phys. Rev. B 59 $1758-75$

[87] Perdew J P, Burke K and Ernzerhof M 1996 Generalized gradient approximation made simple Phys. Rev. Lett. 77 3865-8
[88] Perdew J P, Burke K and Ernzerhof M 1998 Phys. Rev. Lett. 80891

[89] Kittel C 2004 Introduction to Solid State Physics 7th edn (New York: Wiley)

[90] Monkhorst H J and Pack J D 1976 Special points for Brillouinzone integrations Phys. Rev. B 13 5188-92

[91] Bengtsson L 1999 Dipole correction for surface supercell calculations Phys. Rev. B 59 12301-4

[92] Singh-Miller N E and Marzari N 2009 Surface energies, work functions, and surface relaxations of low index metallic surfaces from first-principles Phys. Rev. B 80235407

[93] Calle-Vallejo F and Koper M T M 2012 First-principles computational electrochemistry: achievements and challenges Electrochim. Acta 84 3-11

[94] Goldberg R N and Parker V B 1985 Thermodynamics of solution of $\mathrm{SO}_{2}(\mathrm{~g})$ in water and of aqueous sulfur dioxide solutions (Washington, DC (USA): National Bureau of Standards) https://www.osti.gov/biblio/5818496

[95] Bader R F W 1994 Atoms in Molecules (A Quantum Theory) (Oxford: Clarendon Press)

[96] Bader R F W 1985 Atoms in molecules Acc. Chem. Res. 187

[97] Henkelman G, Arnaldsson A and Jónsson H 2006 A fast and robust algorithm for Bader decomposition of charge density Comput. Mater. Sci. 36 354-60

[98] Baxter G P, Hickey C H and Holmes W C 1907 The vapor pressure OF iodine J. Am. Chem. Soc. 29 127-36

[99] Peterson A A, Abild-Pedersen F, Studt F, Rossmeisl J and Nørskov J K 2010 How copper catalyzes the electroreduction of carbon dioxide into hydrocarbon fuels Energy Environ. Sci. 3 1311-5

[100] Christensen R, Hansen H A and Vegge T 2015 Identifying systematic DFT errors in catalytic reactions Catal. Sci. Technol. 5 4946-9

[101] Granda-Marulanda L P, Rendón-Calle A, Builes S, Illas F, Koper M T M and Calle-Vallejo F 2020 A semiempirical method to detect and correct DFT-based gas-phase errors and its application in electrocatalysis ACS Catal. 10 6900-7

[102] Persson K A, Waldwick B, Lazic P and Ceder G 2012 Prediction of solid-aqueous equilibria: scheme to combine firstprinciples calculations of solids with experimental aqueous states Phys. Rev. B 85235438

[103] Ojha K, Arulmozhi N, Aranzales D and Koper M T M 2020 Double layer at the $\mathrm{Pt}(111)$-aqueous electrolyte interface: potential of zero charge and anomalous Gouy-Chapman screening Angew. Chem. 132 721-5

[104] Autschbach J 2012 Perspective: relativistic effects J. Chem. Phys. 136150902

[105] Migani A and Illas F 2006 A systematic study of the structure and bonding of halogens on low-index transition metal surfaces J. Phys. Chem. B $11011894-906$

[106] Hammer B and Norskov J K 1995 Why gold is the noblest of all the metals Nature 376 238-40

[107] Pašti I A and Mentus S V 2010 Halogen adsorption on crystallographic (111) planes of $\mathrm{Pt}, \mathrm{Pd}, \mathrm{Cu}$ and $\mathrm{Au}$, and on Pd-monolayer catalyst surfaces: first-principles study Electrochim. Acta 55 1995-2003

[108] Garcia-Araez N, Climent V, Herrero E, Feliu J and Lipkowski J 2006 Thermodynamic studies of bromide adsorption at the $\mathrm{Pt}(111)$ electrode surface perchloric acid solutions: comparison with other anions J. Electroanal. Chem. 591 $149-58$

[109] Lipkowski J, Shi Z, Chen A, Pettinger B and Bilger C 1998 Ionic adsorption at the $\mathrm{Au}(111)$ electrode Electrochim. Acta $432875-88$

[110] Roman T and Groß A 2013 Periodic density-functional calculations on work-function change induced by adsorption of halogens on $\mathrm{Cu}(111)$ Phys. Rev. Lett. 110156804

[111] Gossenberger F, Roman T, Forster-Tonigold K and Groß A 2014 Change of the work function of platinum electrodes 
induced by halide adsorption Beilstein J. Nanotechnol. 5 152-61

[112] Roman T, Gossenberger F, Forster-Tonigold K and Groß A 2014 Halide adsorption on close-packed metal electrodes Phys. Chem. Chem. Phys. 16 13630-4

[113] Pašti I, Gavrilov N and Mentus S 2013 Fluorine adsorption on transition metal surfaces: a DFT study J. Serb. Chem. Soc. 78 1763-73

[114] Pašti I A, Gavrilov N M and Mentus S V 2014 DFT study of chlorine adsorption on bimetallic surfaces-case study of $\mathrm{Pd}_{3} \mathrm{M}$ and $\mathrm{Pt}_{3} \mathrm{M}$ alloy surfaces Electrochim. Acta $\mathbf{1 3 0}$ 453-63

[115] Derry G N, Kern M E and Worth E H 2015 Recommended values of clean metal surface work functions $J$. Vac. Sci. Technol. A 33060801

[116] Baker T A, Friend C M and Kaxiras E 2008 Nature of Cl bonding on the $\mathrm{Au}(111)$ surface: evidence of a mainly covalent interaction J. Am. Chem. Soc. 130 3720-1

[117] Oliveira V and Cremer D 2017 Transition from metal-ligand bonding to halogen bonding involving a metal as halogen acceptor a study of $\mathrm{Cu}, \mathrm{Ag}, \mathrm{Au}, \mathrm{Pt}$, and $\mathrm{Hg}$ complexes Chem. Phys. Lett. 681 56-63

[118] Peljhan S and Kokalj A 2009 Adsorption of chlorine on $\mathrm{Cu}(111)$ : a density-functional theory study J. Phys. Chem. C 113 14363-76

[119] Calle-Vallejo F, de Morais R F, Illas F, Loffreda D and Sautet P 2019 Affordable estimation of solvation contributions to the adsorption energies of oxygenates on metal nanoparticles $J$. Phys. Chem. C 123 5578-82

[120] Rendón-Calle A, Builes S and Calle-Vallejo F 2020 Substantial improvement of electrocatalytic predictions by systematic assessment of solvent effects on adsorption energies Appl. Catal. B Environ. 276119147

[121] Mills J N, McCrum I T and Janik M J 2014 Alkali cation specific adsorption onto fcc(111) transition metal electrodes Phys. Chem. Chem. Phys. 16 13699-707

[122] Hachiya T and Itaya K 1992 In situ scanning tunneling microscopy of underpotential deposition in aqueous solution III. Silver adlayers on $\mathrm{Au}(111)$ Ultramicroscopy 42-44 $445-52$ 